\title{
Efeito da redução de luz na seletividade a herbicidas e rendimento de grãos do trigo
}

\section{Effect of light reduction on herbicides selectivity and yield of wheat}

\author{
Rodrigo Rubenich ${ }^{1}$, Carlos Eduardo Schaedler ${ }^{1}$, Renan Ricardo Zandoná1, \\ Ricardo de Melo Scalcon ${ }^{1}$, Pâmela Carvalho de Lima ${ }^{1}$, Diego Martins Chiapinotto ${ }^{1, *}$
}

\begin{abstract}
Resumo - A redução da radiação solar incidente na superfície terrestre pode alterar o comportamento vegetal e a seletividade de herbicidas. O objetivo deste trabalho foi avaliar a seletividade dos herbicidas bentazona, iodosulfuron-methyl-sodium e o rendimento de grãos do trigo, em condições de redução de luminosidade em diferentes estádios fenológicos da cultura. Foram conduzidos dois experimentos, o primeiro (I) em condições controladas e o segundo (II) a campo. Nos dois experimentos foram avaliadas variáveis no trigo em função da aplicação de herbicidas (bentazona, $900 \mathrm{~g} \mathrm{ha}^{-1}$ i.a.; iodosulfuron-methyl-sodium, $5 \mathrm{~g} \mathrm{ha}^{-1}$ i.a.; e testemunha, sem aplicação de herbicida) e da variação da taxa luminosa (testemunha; redução de luz durante todo o ciclo; redução no estádio inicial, da emergência até três folhas; redução no estádio vegetativo, entre três folhas até a emergência completa da inflorescência; e redução na fase reprodutiva, da inflorescência até a colheita). Os resultados demonstram que a redução de luz altera características morfofisiológicas do trigo, aumenta a estatura de plantas, reduz a taxa de transpiração e condutância estomática, mas não interfere na fotossíntese do cereal. No entanto, o rendimento de grãos é afetado negativamente pela redução de luz durante o estádio vegetativo, período ontogenético que coincide com a formação dos principais componentes de rendimento da cultura. Os herbicidas avaliados são seletivos ao trigo, com ou sem redução de luminosidade.
\end{abstract}

Palavras-chave: cereal de inverno, metabolização de herbicidas, radiação solar

Abstract - The solar radiation reduction incident on the terrestrial surface can changes the vegetal behavior and the herbicide selectivity. The aim of this work was to evaluate the herbicide selectivity bentazon, iodosulfuron-methyl-sodium and grain yield of wheat under conditions of reduction of luminosity in different phenological stages of the crop. Two experiments were conducted, the first (I) under controlled conditions and the second (II) in field. In both experiments, wheat was evaluated according to the herbicide application (bentazone, $900 \mathrm{~g} \mathrm{ha}^{-1}$ a.i., iodosulfuron-methyl-sodium, $5 \mathrm{~g} \mathrm{ha}^{-1}$ a.i., and control, without herbicide application) and the variation of the light rate (control; light reduction during the entire cycle; reduction in the initial stage, from emergence to three expanded leaves; reduction in the vegetative stage, three expanded leaves to complete emergence of the inflorescence; and reduction in the reproductive phase, from inflorescence to harvest. The results show that light reduction alters morphophysiological characteristics of wheat, increases plant height, reduces transpiration and stomatal conductance rate, but does not interfere with cereal

Recebido: Setembro 14, 2017. Aceito: Fevereiro 06, 2018.

${ }^{1}$ Universidade Federal do Pampa - UNIPAMPA, Rua Luiz Joaquim de Sá Britto, s/n, Bairro

Promorar, CEP 97650-000, Itaqui, RS, Brasil. E-mail: rodrigorubenich@hotmail.com;

carlosschaedler@unipampa.edu.com; renan_zandona@hotmail.com; ricardounipampa@gmail.com;

carvalhopcl.agro@gmail.com; diego-chiapinotto@hotmail.com 
photosynthesis. However, grain yield is negatively affected by the reduction of light during the vegetative stage, ontogenetic period that coincides with the formation of the main composites of crop yield. The evaluated herbicides are selective to wheat, with or without reduction of luminosity. Keywords: winter cereal, metabolization of herbicides, solar radiation

\section{Introdução}

O trigo (Triticum spp.) é um dos principais cereais produzidos e consumidos no mundo (IBGE, 2016). A interferência de plantas daninhas se destaca entre os principais fatores bióticos limitantes da produtividade da cultura (Agostinetto et al., 2008). O principal método de controle destas espécies é o químico, com bentazona e iodosulfuron-methyl-sodium, herbicidas pós-emergentes seletivos que afetam direta (Schneider et al., 2014) e indiretamente (Costa e Rizzardi, 2014) a fotossíntese das plantas.

A fotossíntese depende da radiação solar incidente sobre a superfície terrestre, que também regula os processos fisiológicos e biofísicos da vegetação (Yang et al., 2013). Assim, é um dos principais fatores determinantes da produtividade agrícola (Song et al., 2016). No entanto, atividades humanas têm causado alterações nos ciclos biogeoquímicos, dentre os quais resulta em menor incidência de radiação solar na superfície do planeta (IPCC, 2007).

Forçantes antropogênicos como fuligem e poeiras formam barreiras, enquanto que alterações no ciclo hidrológico e na cobertura do solo promovem a reflexão da luz solar, impedindo que esta atinja a superfície terrestre (Beyruth, 2008). Nestas condições, com maiores teores de $\mathrm{CO}_{2}$, espécies $\mathrm{C}_{3}$ como o trigo podem ser favorecidas (Way et al., 2014), pois altas intensidades de luz absorvidas por estas plantas causa saturação luminosa, diminuindo a eficiência no uso da radiação (Jiang et al., 2006). Plantas $\mathrm{C}_{3}$ dependem da rubisco para capturar $\mathrm{CO}_{2}$ da atmosfera. No entanto, esta enzima também catalisa a fotorrespiração. Assim, a fotossíntese é limitada em condições ensolaradas (Way et al., 2014).
Pesquisa com simuladores avaliando o impacto da intensidade luminosa constata que a redução da radiação solar, a partir de altos níveis, não interfere na produtividade e aumenta a eficiência do uso da água em trigo (Yang et al., 2013). Por outro lado, a redução na radiação solar altera o comportamento vegetal e a seletividade a herbicidas, fatores estes que são influenciados pelo genótipo da espécie, cultivar e pelo ambiente (Hartwig et al., 2008; Venske et al., 2015). Dessa forma, pesquisas nessa área são importantes para prever o comportamento vegetal sob condições de reduzida luminosidade.

Com base no que foi exposto, o objetivo deste trabalho foi avaliar a seletividade dos herbicidas bentazona e iodosulfuron-methyl-sodium e o rendimento de grãos do trigo, em condições de redução de luminosidade em diferentes estádios fenológicos da cultura.

\section{Material e métodos}

Foram realizados dois experimentos, o primeiro (I) em condições controladas, e o segundo (II) a campo, na safra de 2013. O solo do local é classificado como Plintossolo Háplico (EMBRAPA, 2013), com a seguinte composição química: $\mathrm{pH}=4,8$; $\mathrm{CTC}_{\mathrm{pH} 7,0}=15,6 \mathrm{cmol}_{\mathrm{c}} \mathrm{dm}^{-3} ;$ M.O. $=1,7 \%$; teor de argila $=21 \%$; fósforo $(\mathrm{P})=6,8 \mathrm{mg} \mathrm{dm}^{-3}$; potássio $(\mathrm{K})=48 \mathrm{mg} \mathrm{dm}^{-3}$. O clima, pela classificação de Köppen, é do tipo Cfa, subtropical úmido sem estação seca definida, com verões quentes (Peel et al., 2007). Dados da temperatura média e precipitação pluviométrica mensal, durante a condução dos experimentos, podem ser visualizados na Figura 1. A cultivar utilizada foi a OR Sementes/Biotrigo Quartzo, de ciclo médio, recomendada para as regiões tritícolas do Sul e Sudeste do Brasil. 

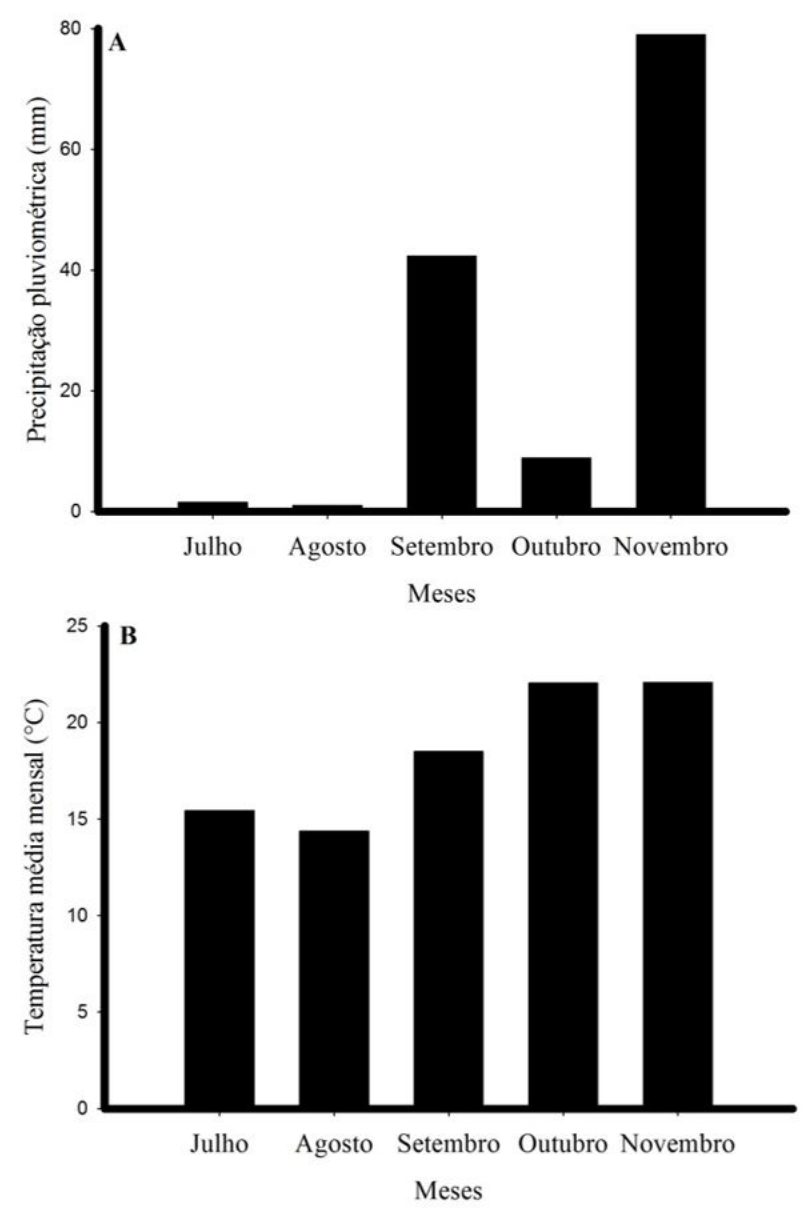

Figura 1. Precipitação pluviométrica $(\mathrm{mm})$ e temperatura média mensal $\left({ }^{\circ} \mathrm{C}\right),(\mathrm{A})$ e $(\mathrm{B})$, respectivamente, coletados na estação meteorológica automática $\left(29^{\circ} 9^{\prime} 21.37^{\prime \prime} \mathrm{S} ; 56^{\circ} 33^{\prime} 9.97^{\prime \prime} \mathrm{W}\right)$, durante a condução dos experimentos - de 24 de Julho à 6 de novembro de 2013.

O experimento I foi realizado em casa de vegetação, com semeadura no dia 31 de julho e conduzido até meados de setembro, em vasos com capacidade volumétrica de 8 litros, com seis plantas por vaso, correspondendo a 330 plantas $\mathrm{m}^{-2}$. O experimento II foi conduzido a campo, com semeadura no dia 24 de julho e colheita no dia 6 de novembro de 2013, em sistema plantio direto, com densidade de 330 plantas $\mathrm{m}^{-2}$. O delineamento experimental foi em blocos inteiramente casualisados, com quatro repetições para o experimento I, e cinco repetições para o experimento II. Os experimentos foram arranjados em esquema fatorial $3 \times 5$, com parcelas subdivididas; onde os diferentes estádios da cultura sob redução de luminosidade foram dispostas em faixas, e o fator herbicida, inteiramente casualisado dentro de cada faixa.

$\mathrm{O}$ primeiro fator foi composto pelos herbicidas: bentazona $\left(900 \mathrm{~g} \mathrm{ha}^{-1}\right.$ i.a. - Basagran ${ }^{\circledR}$ $600,600 \mathrm{~g} \mathrm{~L}^{-1}$ i.a., SL, Basf), iodosulfuronmethyl-sodium ( $5 \mathrm{~g} \mathrm{ha}^{-1}$ i.a. - Hussar, $50 \mathrm{~g} \mathrm{Kg}^{-1}$ i.a., WG, Bayer), e testemunha sem aplicação de herbicida. O segundo fator foram diferentes níveis de luz $(50 \%$ de redução artificial, utilizando telado de polipropileno) em 5 estádios fenológicos do trigo, conforme escala proposta por Zadoks et al. (1974): 1) Testemunha (luz natural em todo ciclo da cultura);2) redução de luz durante ciclo total, ou seja, de Z0.9 (50\% dos coleóptilos emergidos) até a colheita; 3) telado no estádio inicial, Z0.9 até Z1.3 (três folhas expandidas); 4) telado no estádio vegetativo, Z1.3 até Z5.9 (emergência completa da inflorescência); e 5) telado no reprodutivo, Z5.9 até a colheita.

Quando a cultura apresentou estádio até 3 folhas e 1 afilho (Z1.3 \& Z2.1), foram aplicados os tratamentos herbicidas. A aplicação ocorreu utilizando pulverizador pressurizado a $\mathrm{CO}_{2}$, munido de pontas (distantes $0,5 \mathrm{~m}$ ) com jato plano, tipo leque, modelo XR 110.015, com pressão de trabalho de $250 \mathrm{kPa}$ e barra postada a $0,5 \mathrm{~m}$ do alvo. A velocidade média do vento durante a aplicação foi de $5,4 \mathrm{Km} \mathrm{h}^{-1}$, demais condições ambientais dentro do recomendado pelos fabricantes (AGROFIT, 2016).

No experimento I, foi avaliada a estatura de plantas aos 7, 14 e 28 dias após os tratamentos (DAT). A fotossíntese, condutância estomática e transpiração do trigo foram avaliadas aos 12 dias após inserção do telado e sete dias após tratamento herbicida, e aos 29 dias após inserção do telado e 24 dias após aplicação. Para variáveis fisiológicas utilizou-se analisador de gases no infravermelho (IRGA) LC PRO, realizadas entre 9-11:30 horas.

No experimento II, foi realizada adubação de base na linha de semeadura com $150 \mathrm{~kg} \mathrm{ha}^{-1} \mathrm{da}$ 
fórmula NPK 05-20-20. A adubação de cobertura, em forma de ureia, foi com $66 \mathrm{~kg}$ de $\mathrm{N} \mathrm{ha}^{-1}$ no início dos primeiros afilhos e $44 \mathrm{~kg}^{\mathrm{de}} \mathrm{N} \mathrm{ha}^{-1}$ no alongamento do colmo principal. As parcelas continham $0,85 \mathrm{~m} \mathrm{x} \mathrm{7,5} \mathrm{m,} \mathrm{subdividas} \mathrm{em}$ $0,85 \mathrm{~m} \times 2,5 \mathrm{~m}$, onde cada parcela apresentava cinco linhas espaçadas em 0,17 m. Aos 14 e 33 dias após o tratamento (DAT) foi avaliada a estatura de plantas, utilizando oito plantas representativas escolhidas aleatoriamente nas três linhas centrais de cada unidade experimental. $\mathrm{Na}$ fase reprodutiva foi avaliado o número de espiguetas por espiga; número de grãos por espiga e rendimento de grãos. A colheita das espigas foi realizada manualmente nas três linhas centrais, em área de $1,02 \mathrm{~m}^{2}$. Após, efetuou-se seleção aleatória de 10 espigas do colmo principal por parcela para avaliar o número de espiguetas por espiga e grãos por espiga. Para o rendimento de grãos, coletaram-se todas as espigas das três linhas centrais, realizando-se debulha manual. Os grãos foram pesados e a umidade corrigida para $13 \%$.

Os dados dos experimentos foram submetidos à análise de variância pelo teste $\mathrm{F}(\mathrm{p} \leq 0,05)$. Para variáveis que não apresentaram interação entre os fatores realizou-se o teste de médias pela diferença mínima significativa, DMS de Fischer $(p \leq 0,05)$.

\section{Resultados e discussão}

No experimento I houve diferença para a variável estatura, transpiração e condutância estomática, em resposta à redução de luminosidade em diferentes estádios do trigo. A fotossíntese apresentou diferença para o fator herbicida. No experimento II, houve diferença para a variável estatura, número de espiguetas por espiga e número de grãos por espiga, em resposta à redução de luminosidade em diferentes estádios da cultura. Para o rendimento de grãos, houve interação entre redução de luz e os diferentes herbicidas avaliados.

No experimento I, para a variável estatura de plantas aos 7, 14 e 28 DAT, os maiores valores foram obtidos com os tratamentos com redução de luz em ciclo total, inicial e vegetativo
(Figuras 2A, B e C). Referente aos herbicidas houve interação na primeira avaliação (Figura 2D) e não diferiram nas demais épocas (dados não apresentados).

Para a variável transpiração, na primeira e na segunda época avaliada, o tratamento com redução de luz em ciclo total e na fase vegetativa obtiveram menores índices, respectivamente (Figuras 3A e B). Para os tratamentos herbicidas, não houve diferença para essa variável (dados não apresentados). Para a condutância estomática, na primeira avaliação, a fase inicial foi a que demonstrou maior taxa (Figura 3C). Na segunda época avaliada, os maiores valores encontrados foram sem redução de luz durante todo ciclo (Figura 3D). Para o fator herbicida, não ocorreram alterações (dados não apresentados).

Para a variável fotossíntese, na primeira e na segunda época avaliada não houve diferença, em resposta aos ambientes com ou sem redução de luminosidade nos diferentes estádios do trigo (Figuras 4A e B). No entanto, houve diferenças para os tratamentos herbicidas. Na primeira avaliação o bentazona obteve maior taxa fotossintética. O mesmo ocorreu com iodosulfuron-methyl-sodium, na segunda avaliação (Figuras 4C e D).

No experimento II, para a variável estatura, a redução de luz causou maior crescimento. Aos 14 e 33 DAT, os tratamentos com redução luminosa em ciclo total, estádio inicial e vegetativo apresentaram maior crescimento (Figura 5A e B). Não foi observada diferença para o fator herbicida (dados não apresentados). Referente aos componentes de rendimento do trigo, o número de grãos por espiga foi maior no tratamento com redução de luz em ciclo total (Figura 5C) e não apresentou diferença relacionado aos tratamentos herbicidas (Figura 5D). Para o número de espiguetas por espiga, os maiores valores foram obtidos sob redução de luz em fase inicial seguido por ciclo total (Figura 5E). Para o fator herbicida, não houve alteração significativa nos valores obtidos (Figura 5F). 

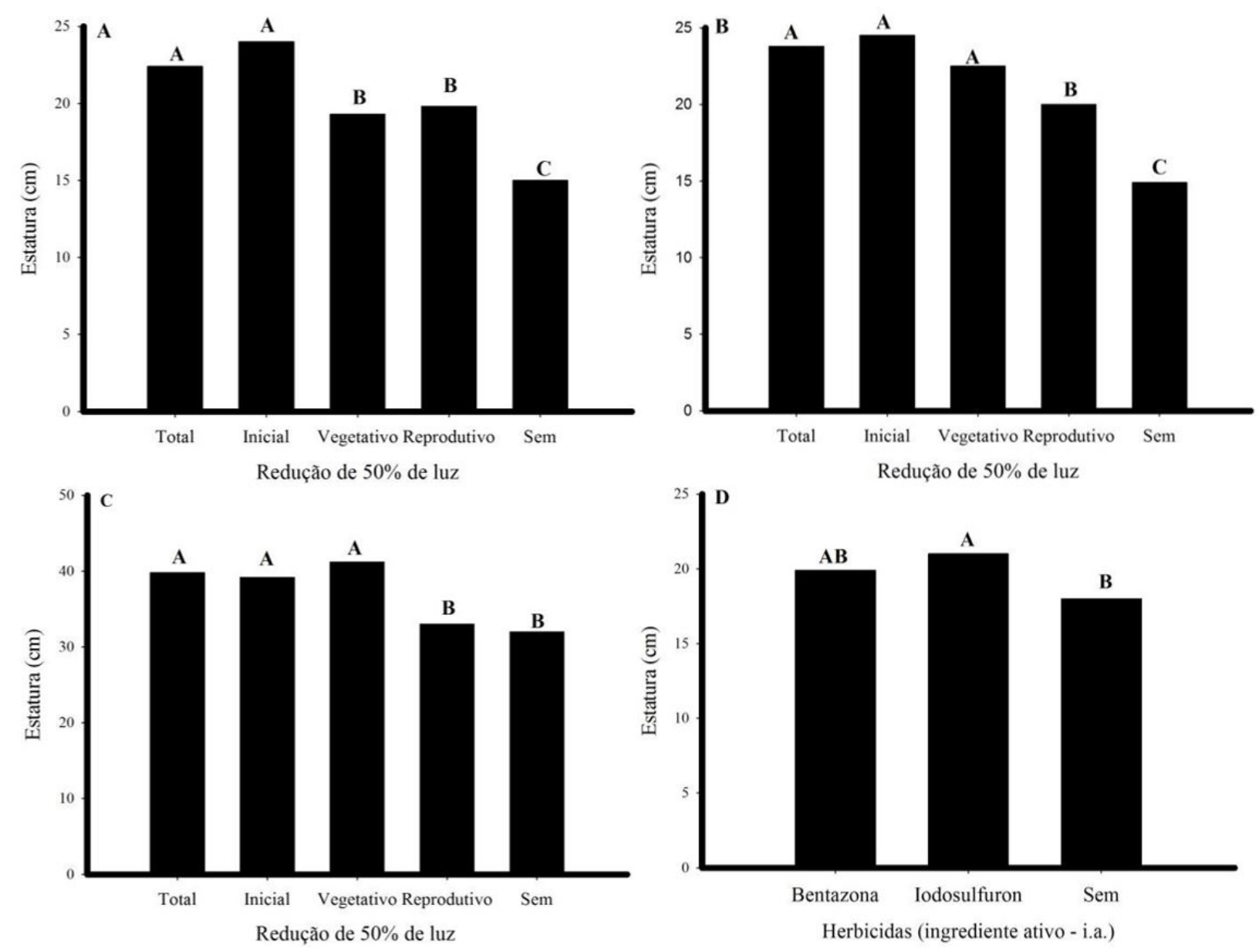

Figura 2. Estatura de plantas (cm), avaliada em casa de vegetação aos 7, 14 e 28 dias após o tratamento (DAT); (A), (B) e (C) referentes à redução de luminosidade, respectivamente; (D) relacionado à primeira avaliação com aplicação herbicida. Médias dos tratamentos, seguidas de letras distintas, diferem entre si pelo teste DMS de Fischer $(\mathrm{p} \leq 0,05)$.

Para a variável rendimento de grãos houve interação entre os tratamentos herbicidas e ambientes. Na testemunha sem aplicação de herbicida, os tratamentos sob redução de $50 \%$ de luz, exceto no período vegetativo, não diferiram do tratamento com luz natural. Para o herbicida iodosulfuron-methyl-sodium, exceto com redução luminosa no período vegetativo, os tratamentos sob redução de luz não diferiram com o de luz natural. Para o herbicida bentazona, o rendimento de grãos sob redução de luz em período total e em estádio inicial de desenvolvimento da cultura foi maior comparada com luz natural, que não diferiu do estádio reprodutivo, e menor produtividade foi observada na fase vegetativa (Figura 6).

Constata-se, de modo geral em ambos os experimentos, maior estatura de plantas em condições de redução de luz. Os vegetais possuem fotorreceptores que detectam a qualidade de luz pela alteração da razão vermelho: vermelho extremo (V:Ve). As respostas morfofisiológicas à redução da razão V:Ve incluem aumento de estatura e área foliar (Liu et al., 2009). O aumento na estatura permite maior formação do dossel vegetal e é causada pelo sombreamento ou a presença de plantas daninhas (Agostinetto et al., 

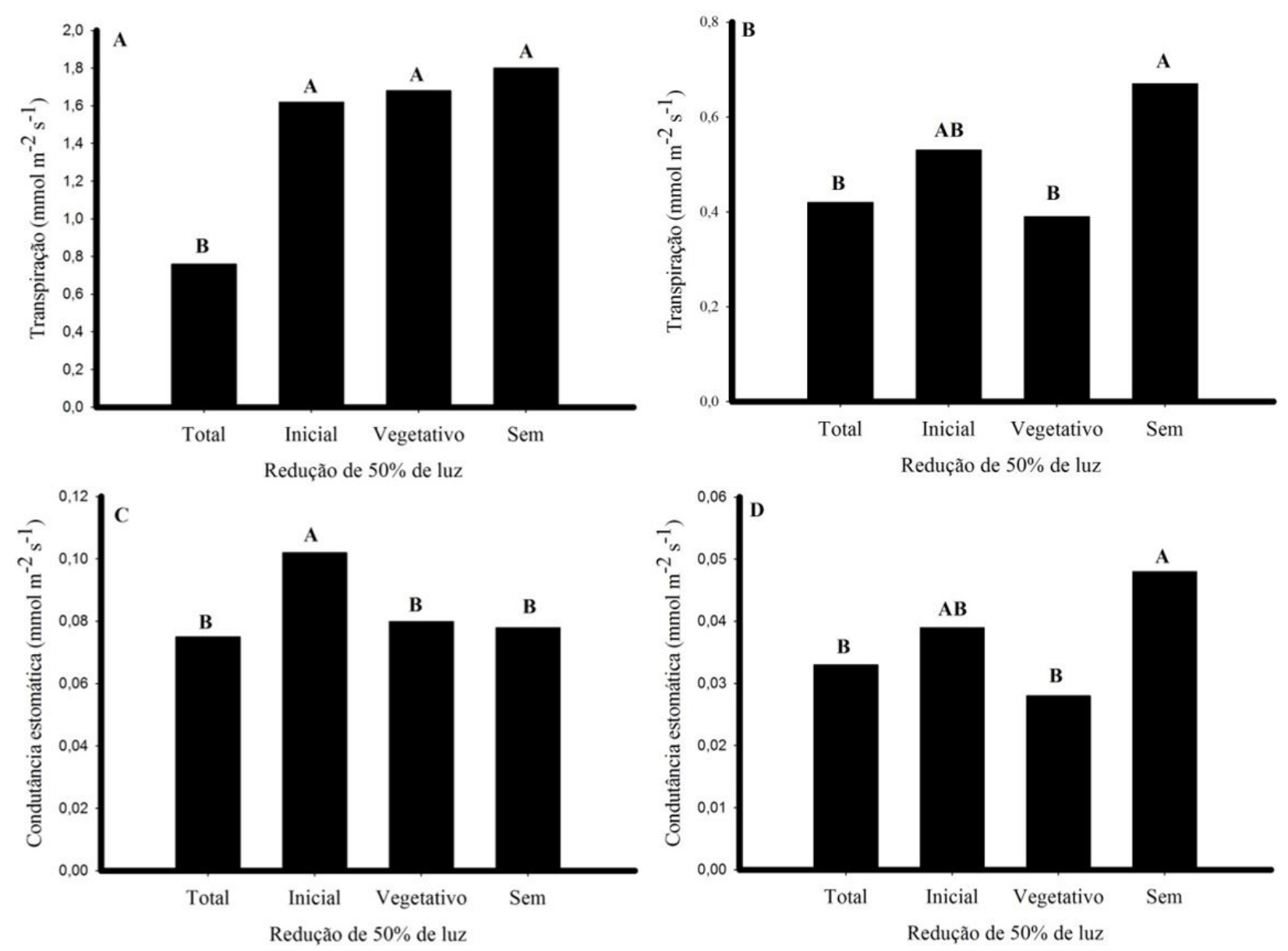

Figura 3. Transpiração $\left(\mathrm{mmol} \mathrm{m} \mathrm{m}^{-2} \mathrm{~s}^{-1}\right)$ em primeira (A) e segunda época (B), e condutância estomática $\left(\mathrm{mmol} \mathrm{m} \mathrm{m}^{-2} \mathrm{~s}^{-1}\right.$ ) em primeira (C) e segunda época (D), sob de redução de luminosidade. Médias, seguidas de letras distintas, diferem pelo teste DMS de Fischer $(\mathrm{p} \leq 0,05)$.

2008; Schaedler et al., 2009). Assim, as plantas investem maior proporção de fotoassimilados no aumento da área foliar, otimizando a captação de luz (Gobbi et al., 2011).

A redução da razão $\mathrm{V}$ :Ve pode alterar o teor de clorofila e fotossíntese das plantas (Liu et al., 2009), principal fator determinante para a produção vegetal (Song et al., 2016). No entanto, nesta pesquisa a fotossíntese não apresentou alteração em condições de redução de luz, pois este processo também depende de água e temperatura (Galmés et al., 2007). A redução da radiação solar diminui a evaporação da água e a temperatura, aumentando o grau de umidade do solo (Stanhill e Cohen, 2001).

A cultura do trigo requer em média $490 \mathrm{~mm}$ de água (Ouda et al., 2015), porém, durante a realização do experimento ocorreu déficit hídrico, totalizando 132,66 mm durante o ciclo da cultura - Figura 1A. Estes dados constatam que nestas condições e sob redução de luz, o cereal continua a fotossitentizar com maior eficiência do uso de água (Yang et al., 2013). As modificações destes fatores elucidam porque as variáveis fisiológicas de transpiração e condutância estomática apresentaram menores índices sob redução de luminosidade. 

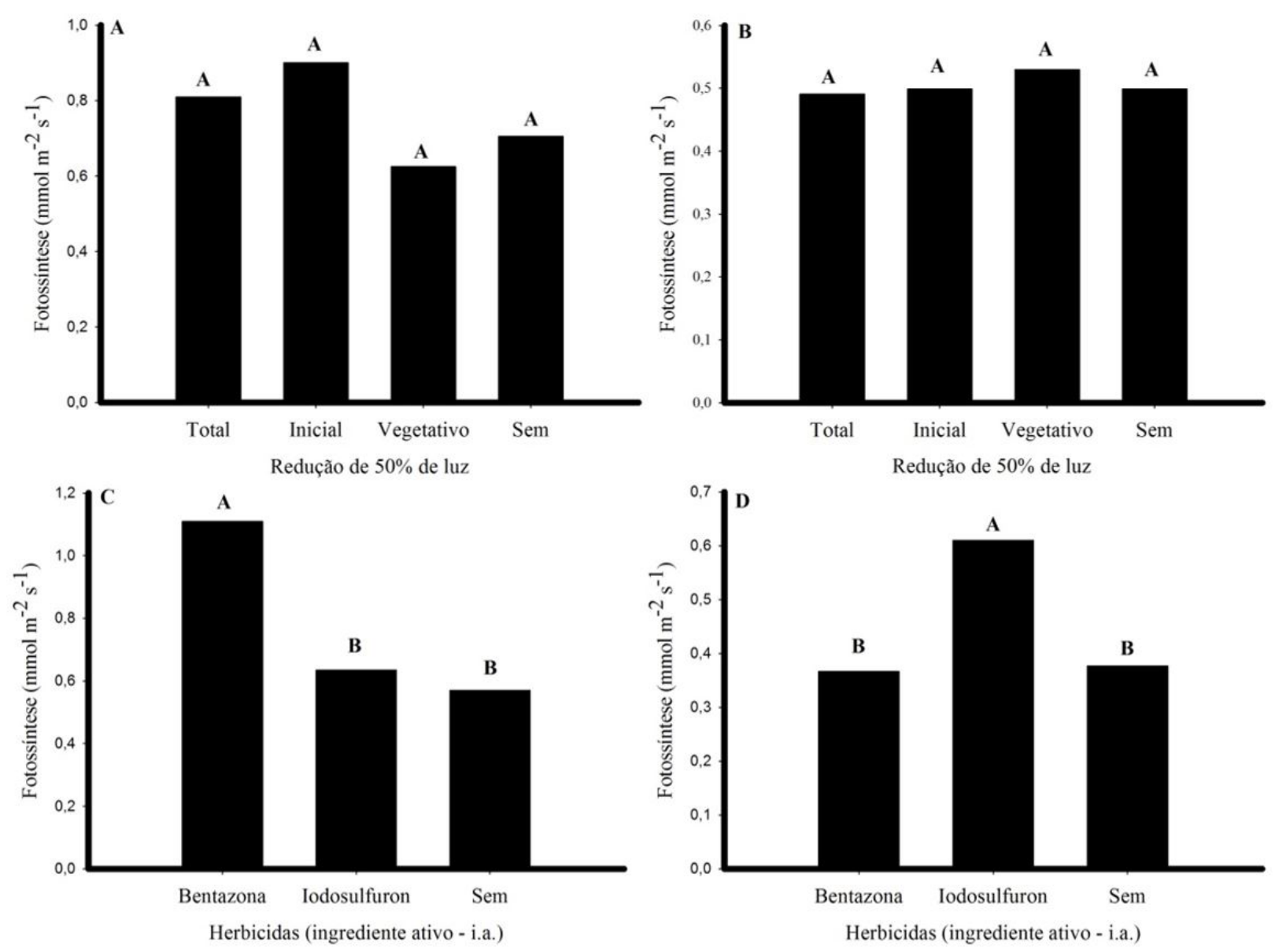

Figura 4. Fotossíntese $\left(\mathrm{mmol} \mathrm{m} \mathrm{m}^{-2} \mathrm{~s}^{-1}\right)$ em primeira $(\mathrm{A})$ e segunda época $(\mathrm{B})$, relacionada com tratamentos de redução de luminosidade; e em primeira (C) e segunda época (D) relacionada com aplicação herbicida. Médias dos tratamentos, seguidas de letras distintas, diferem entre si pelo teste DMS de Fischer $(\mathrm{p} \leq 0,05)$.

O fechamento estomático ocorre quando os níveis de luz estão abaixo da radiação fotossinteticamente ativa (PAR), altas temperaturas, e até mesmo para evitar o estresse hídrico, reduzindo a quantidade de $\mathrm{CO}_{2}$ absorvido (Brodribb e Hill, 2000).

A redução no rendimento de grãos, com redução de luz entre o estádio de três folhas expandidas até o início da floração, relaciona-se ao período ontogenético da cultura. Após a germinação, o ápice de crescimento do trigo localiza-se abaixo da superfície do solo até o momento do aparecimento do primeiro primórdio da espigueta no ápice, estádio denominado de duplo anel
(Rodrigues et al., 2011a). O estádio de duplo anel caracteriza o final da fase vegetativa e o início do período reprodutivo e ocorre quando a planta apresenta de 2 a 4 folhas, ou seja, o período reprodutivo não se inicia com a extrusão das anteras na espiga. A partir do estádio de duplo anel, o primórdio diferencia as demais espiguetas na espiga até desenvolver a última espigueta, estádio de espigueta terminal. Nesse estádio ocorre a definição dos principais componentes de rendimento do trigo (Rodrigues et al., 2011b).

Em relação aos herbicidas, no experimento I, pode-se observar maior estatura do trigo 
logo após a aplicação, onde o herbicida iodosulfuron-methyl-sodium estimulou maior crescimento. Essa diferença não foi visualizada nas demais avaliações, pela possível metabolização dos produtos decorridos 14 dias após a aplicação. A seletividade dos herbicidas ALS na cultura do
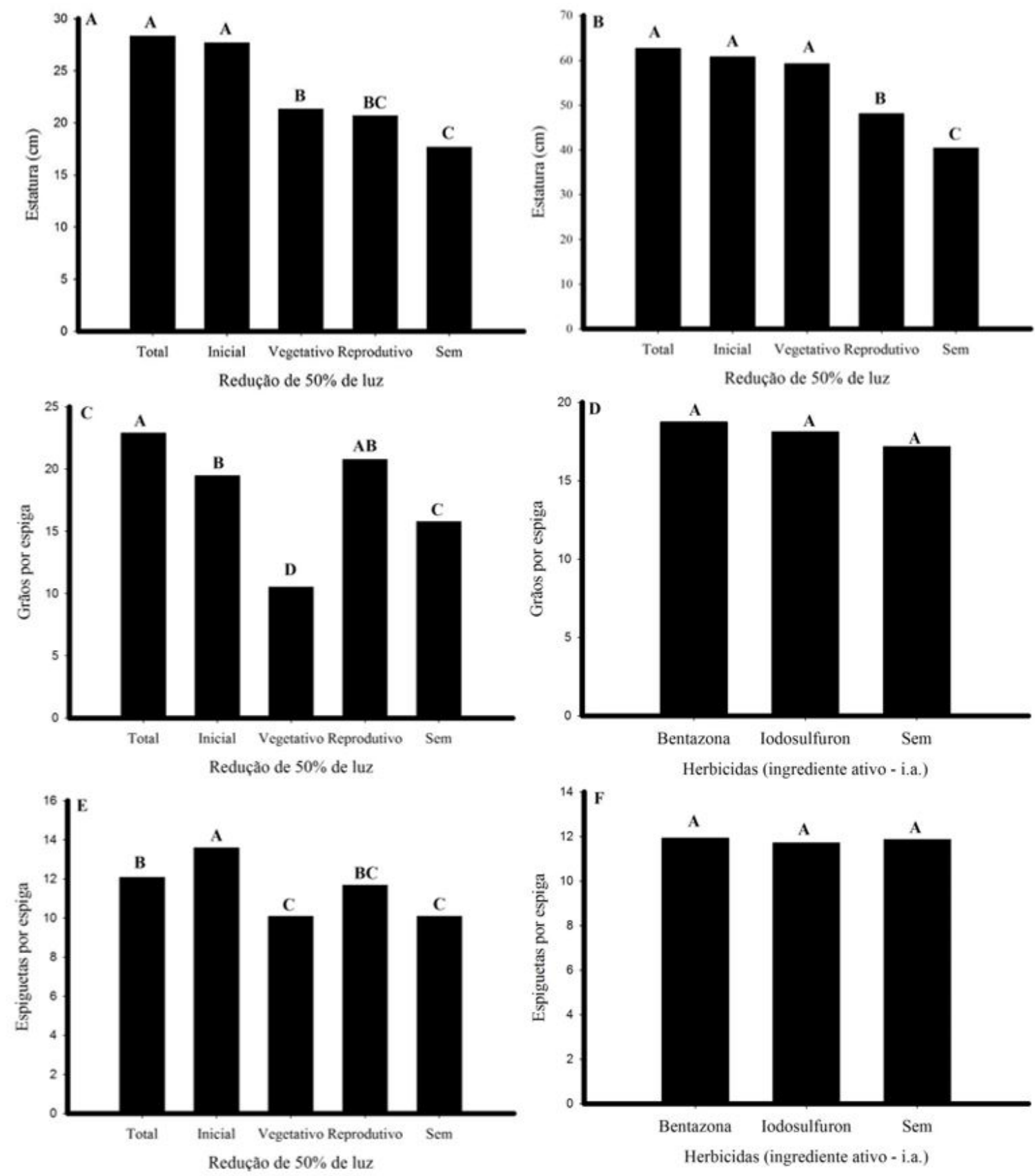

Figura 5. Estatura de plantas (cm), avaliada a campo aos 14 e 33 dias após o tratamento (DAT); (A) e (B) referentes à redução de luminosidade, respectivamente. Grãos por espiga, relacionado à redução de luminosidade (C) e com aplicação herbicida (D). Número de espiguetas por espiga, relacionado à redução de luminosidade (E) e com aplicação herbicida (F). Médias dos tratamentos, seguidas de letras distintas, diferem entre si pelo teste DMS de Fischer $(\mathrm{p} \leq 0,05)$. 


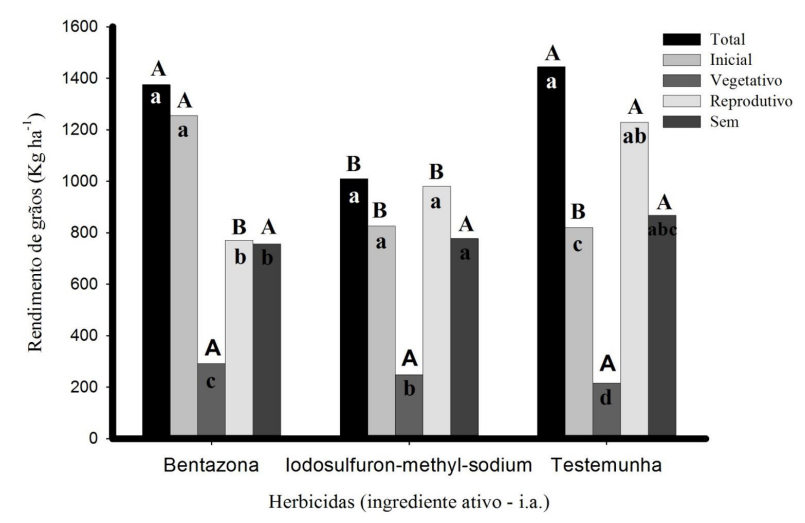

Figura 6. Rendimento de grãos de trigo $\left(\mathrm{kg} \mathrm{ha}^{-1}\right) \mathrm{em}$ relação aos tratamentos de redução de luminosidade e seletividade de herbicidas. Letras maiúsculas comparam os tratamentos luminosidade em diferentes tratamentos herbicidas, letras minúsculas comparam tratamento luminosidade em cada tratamento herbicida. Médias dos tratamentos, seguidas de letras distintas, diferem entre si pelo teste de DMS de Fischer $(\mathrm{p} \leq 0,05)$.

trigo (Hartwig et al., 2008), como o iodosulfuronmethyl-sodium, deve-se à metabolização ou degradação da molécula em formas não tóxicas (Yu e Powles, 2014).

A metabolização e a conjugação de herbicidas nas plantas são mediadas, principalmente, pelas enzimas citocromo- $\mathrm{P}_{450}$-monooxigenase $(\mathrm{P} 450) \mathrm{e}$ glutationa-S-transferase (GST), respectivamente. Essas inativam os herbicidas antes que cheguem ao local de ação na célula e causem danos às plantas (Powles e Yu, 2010). O nível de transcrição das P450 e GST são estimuladas devido ao tratamento com bentazona (Zhu et al., 2009), indicando também ser esse o mecanismo responsável pela seletividade em culturas agrícolas.

A habilidade da planta em degradar herbicidas depende das condições ambientais preponderantes, que devem ser próximas às condições ótimas para o desenvolvimento da cultura (Queiroz et al., 2017), pois a seletividade desses produtos devido ao metabolismo diferencial requer aporte de energia celular (Carvalho et al., 2009), proveniente da fotossíntese. Assim, justifica o acréscimo dessa variável com a aplicação dos herbicidas. O bentazona por ser um herbicida de contato, pouco translocado (Schneider et al., 2014), age rapidamente, explicando inicial acréscimo. Já o herbicida iodosulfuron-methyl sofre translocação na planta (Costa e Rizzardi, 2014), explicando acréscimo na segunda avaliação.

Cabe destacar que os herbicidas avaliados não interferiram no rendimento de grãos da cultura. Assim, o bentazona e o iodosulfuron-methylsodium são seletivos à cultura do trigo, com ou sem redução de luminosidade, corroborando com os resultados de outra pesquisa (Agostinetto et al., 2016). O maior rendimento de grãos, observado com a aplicação de bentazona sob redução de luz em ciclo total e inicial deve ser melhor elucidado. Até o momento, sabe-se que as $\mathrm{P} 450$ pertencem a uma superfamília de monooxigenases multifuncionais (Park et al., 2015). As monooxigenações catalisadas com essas enzimas dependem da doação de elétrons provenientes basicamente de NADPH (forma reduzida do dinucleotídeo de adenina e nicotinamida fosfato) (Jensen et al., 2011). A aplicação desse herbicida aumenta a transcrição do gene que codifica $\mathrm{NADP}^{+}$, enzima responsável por catalisar a produção de NADPH. Além disso, aumenta a anidrase carbônica, que enriquece a concentração de $\mathrm{CO}_{2}$ para promover a fixação de carbono (Zhu et al., 2009).

\section{Conclusões}

A redução de luz em diferentes estádios do trigo altera características morfofisiológicas da cultura, aumenta a estatura de plantas, reduz a taxa de transpiração e condutância estomática, mas não interfere na fotossíntese. $\mathrm{O}$ rendimento de grãos do cereal é afetado, com ou sem aplicação de herbicidas, pela redução de luz entre o estádio fenológico de três folhas expandidas até a emergência completa da inflorescência, período ontogenético que coincide com a formação dos principais componentes de rendimento da cultura. Os herbicidas avaliados são seletivos à cultura, com ou sem redução da luminosidade. 


\section{Referências}

Agostinetto, D.; Perboni, L.T.; Langaro, A.C.; Gomes, J.; Fraga, D.S.; Franco, J.J. Changes in photosynthesis and oxidative stress in wheat plants submmited to herbicides application. Planta Daninha, v.34, n.1, p.1-9, 2016.

Agostinetto, D.; Rigoli, R.P.; Schaedler, C.E.; Tironi, S.P.; Santos, L.S. Período crítico de competição de plantas daninhas com a cultura do trigo. Planta Daninha, v.26, n.2, p.271-278, 2008. AGROFIT - Sistema de Agrotóxicos Fitossanitários. Relatório de produtos formulados. Disponível em: $<w w w . a g r i c u l t u r a . g o v . b r / a g r o f i t>>$. Acesso em: 26 abr. 2016.

Beyruth, Z. Água, agricultura e as alterações climáticas globais. Revista Tecnologia \& inovação Agropecuária, v.1, p.74-89, 2008.

Brodribb, T.J.; Hill, R.S. Increases in water potential gradient reduce xylem conductivity in whole plants. Evidence from a low-pressure conductivity method. Plant Physiology, v.123, n.3, p.1021-1028, 2000.

Carvalho, S.J.P.; Nicolai, M.; Ferreira, R.R.; Figueira, A.V.O.; Christoffoleti, P.J. Herbicide selectivity by differential metabolism: considerations for reducing crop damages. Scientia Agrícola, v.66, n.1, p.136-142, 2009.

Costa, L.O.; Rizzardi, M.A. Resistance of Raphanus raphanistrum to the herbicide metsulfuron-methyl. Planta Daninha, v.32, n.1, p.181-187, 2014.

EMBRAPA - Empresa Brasileira de Pesquisa Agropecuária. Sistema brasileiro de classificação de solos. 3.ed. Brasília: Embrapa, 2013. 353p.

Galmés, J.; Medrano, H.; Flexas, J. Photosynthetic limitations in response to water stress and recovery in Mediterranean plants with different growth forms. The New Phytologist, v.175, n.1, p.8193, 2007.
Gobbi, K.F.; Garcia, R.; Ventrella, M.C.; Neto, A.M.F.G.; Rocha, G.C. Área foliar específica e anatomia foliar quantitativa do capim-braquiária e do amendoim-forrageiro submetidos a sombreamento. Revista Brasileira de Zootecnia, v.40, n.7, p.1436-1444, 2011.

Hartwig, I.; Bertan, I.; Galon, L.; Noldin, J.A.; Concenço, G.; Silva, A.F.; et al. Tolerância de trigo (Triticum aestivum) e aveia (Avena sp.) a herbicidas inibidores da enzima acetolactato sintase (ALS). Planta Daninha, v.26, n.2, p.361368, 2008.

IBGE - Instituto Brasileiro de Geografia e Estatística. Levantamento sistemático da produção agrícola. Disponível em: <www.ibge. gov.br>>. Acesso em: 26 abr. 2016.

IPCC - Intergovernmental Panel on Climate Change. Climate Change 2007: full report. 2007. Disponível em: <www.ipcc.ch $>>$. Acesso em: 18 jul. 2016.

Jensen, K.; Jensen, P.E.; Moller, B.L. Light-driven cytochrome P450 hydroxylations. Chemistry \& Biology, v.6, n.6, p.533-539, 2011.

Jiang, C.-D.; Gao, H.-Y.; Zou, Q.; Jiang, G.-M.; Li, L.-H. Leaf orientation, photorespiration and xanthophyll cycle protect young soybean leaves against high irradiance in field. Environmental and Experimental Botany, v.55, n.1-2, p.8796, 2006.

Liu, J.G.; Mahoney, K.J.; Sikkema, P.H.; Swanton, C.J. The importance of light quality in crop-weed competition. Weed Research, v.49, n.2, p.217224, 2009.

Ouda, S.; Noreldin, T.; Abd El-Latif, K. Water requirements for wheat and maize under climate change in North Nile Delta. Spanish Journal of Agricultural Research, v.13, n.1, p.1-10, 2015.

Park, J.H.; Lee, S.H.; Cha, G.S.; Choi, D.S.; Nam, D.H.; Lee, J.H.; et al. Cofactor-free lightdriven whole-cell cytochrome P450 catalysis. 
Angewandte Chemie International Edition, v.54, n.3, p.969-973, 2015.

Peel, M.C.; Finlayson, B.L.; McMahon, T.A. Updated world map of the Köppen-Geiger climate classification. Hydrology and Earth System Sciences, v.11, p.1633-1644, 2007.

Powles, S.; Yu, Q. Evolution in action: plants resistant to herbicides. Annual Review of Plant Biology, v.61, n.1, p.317-347, 2010.

Queiroz, A.R.S.; Vidal, R.A.; Nava, I.C.; Pacheco, M.T.; Federizzi, L.C.; Xavier, E. Selectivity of iodosulfuron-methyl to oat cultivars. Planta Daninha, v.35, p.1-9, 2017.

Rodrigues, O.; Teixeira, M.C.C.; Costenaro, E.R. Manejo de trigo para alta produtividade. Plantio Direto, v.20, n.123, p.19-24, 2011 a.

Rodrigues, O.; Haas, J.C.; Costenaro, E.R. Manejo de trigo para alta produtividade II: caracterização ontogenética. Plantio Direto, v.20, n.125, p.1013, 2011b.

Schaedler, C.E.; Fleck, N.G.; Ferreira, F.B.; Lazaroto, C.A.; Rizzardi, M.A. Características morfológicas em plantas de cultivares de aveia como indicadoras do potencial competitivo com plantas daninhas. Ciência Rural, v.39, n.5, p.1313-1319, 2009.

Schneider, M.V.; Rosa, M.F.; Lobo, V. da S.; Baricatti, R.A. Degradação fotocalítica de bentazone com TiO2. Engenharia Sanitaria e Ambiental, v.19, n.1, p.61-66, 2014.

Song, Q.; Chu, C.; Parry, M.A.J.; Zhu, X.-G. Genetics-based dynamic systems model of canopy photosynthesis: the key to improve light and resource use efficiencies for crops. Food and Energy Security, v.5, n.1, p.18-25, 2016.

Stanhill, G.; Cohen, S. Global dimming: a review of the evidence for a widespread and significant reduction in global radiation with discussion of its probable causes and possible agricultural consequences. Agricultural and Forest Meteorology, v.107, p.255-278, 2001.

Venske, E.; Schaedler, C.E.; Bahry, C.A.; Camargo, T.O.; Zimmer, P.D. Fatores abióticos sobre o efeito de herbicidas na qualidade fisiológica de sementes de arroz. Ciência Agronômica, v.46, n. 4, p.818-825, 2015.

Way, D.A.; Katul, G.G.; Manzoni, S.; Vico, G. Increasing water use efficiency along the $\mathrm{C} 3$ to C4 evolutionary pathway: a stomatal optimization perspective. Journal of Experimental Botany, v.65, n.13, p.3683-3693, 2014.

Yang, X.; Asseng, S.; Wong, M.T.F.; Yu, Q.; Li, J.; Liu, E. Quantifying the interactive impacts of global dimming and warming on wheat yield and water use in China. Agricultural and Forest Meteorology, v.182-183, p.342-351, 2013.

Yu, Q.; Powles, S.B. Resistance to AHAS inhibitor herbicides: current understanding. Pest Management Science, v.70, n.9, p.1340-1350, 2014.

Zadoks, J.C.; Chang, T.T.; Konzak, C.F. A decimal code for the growth stages of cereals. Weed Research, v.14, p.415-421, 1974.

Zhu, J.; Patzoldt, W.L.; Radwan, O.; Tranel, P.J.; Clough, S. Effects of photosystem-II-interfering herbicides atrazine and bentazon on the soybean transcriptome. The Plant Genome, v.2, n.2, p.191-205, 2009. 